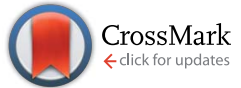

Cite this: Chem. Sci., 2016, 7, 6153

Received 25th April 2016 Accepted 1st June 2016

DOI: $10.1039 / c 6 s c 01793 b$

www.rsc.org/chemicalscience

\section{Simultaneous fluorescence imaging of hydrogen peroxide in mitochondria and endoplasmic reticulum during apoptosis $\uparrow$}

\begin{abstract}
Haibin Xiao, Ping Li, ${ }^{*}$ Xiufen Hu, Xiaohui Shi, Wen Zhang and Bo Tang*
Cell apoptosis is a biochemical and molecular pathway essential for maintaining cellular homeostasis. It is an integrated process involving in a series of signal transduction cascades. Moreover, the apoptotic pathways may be initiated inside various subcellular organelles. Increasing evidence indicates that hydrogen peroxide $\left(\mathrm{H}_{2} \mathrm{O}_{2}\right)$ is closely related to cell apoptosis, particularly in the mitochondria. However, during the apoptotic process, the synergetic variation of $\mathrm{H}_{2} \mathrm{O}_{2}$ levels in different compartments is seldom explored, particularly in two important organelles: mitochondria and endoplasmic reticulum (ER). To solve this problem, we developed two new organelle-specific fluorescent probes termed $\mathrm{MI}-\mathrm{H}_{2} \mathrm{O}_{2}$ and $\mathrm{ER}-\mathrm{H}_{2} \mathrm{O}_{2}$ that can detect $\mathrm{H}_{2} \mathrm{O}_{2}$ in mitochondria and $\mathrm{ER}$, respectively or simultaneously. Experimental results demonstrated that $\mathrm{MI}-\mathrm{H}_{2} \mathrm{O}_{2}$ and $\mathrm{ER}-\mathrm{H}_{2} \mathrm{O}_{2}$ display distinguishable excitation and emission spectra, as well as excellent organelle targeting capabilities. Therefore, we used $\mathrm{MI}-\mathrm{H}_{2} \mathrm{O}_{2}$ and $\mathrm{ER}-\mathrm{H}_{2} \mathrm{O}_{2}$ to successfully image exogenous or endogenous hydrogen peroxide in the mitochondria and ER. Interestingly, during diverse apoptotic stimuli, dual-color fluorescence imaging results revealed that the changes of $\mathrm{H}_{2} \mathrm{O}_{2}$ levels in mitochondria and ER are different. The $\mathrm{H}_{2} \mathrm{O}_{2}$ levels are enhanced in both the mitochondria and ER during the L-buthionine sulfoximine (BSO)-treated cell apoptosis process. During mitochondria-oriented apoptosis induced by carbonyl cyanide $m$-chlorophenylhydrazone (CCCP) or rotenone, $\mathrm{H}_{2} \mathrm{O}_{2}$ levels prominently and continuously increase in the mitochondria, whereas the $E R \mathrm{H}_{2} \mathrm{O}_{2}$ levels were found to rise subsequently after a delay. Moreover, during ER-oriented apoptosis induced by tunicamycin, ER is the major site for overproduction of $\mathrm{H}_{2} \mathrm{O}_{2}$, and delayed elevation of the $\mathrm{H}_{2} \mathrm{O}_{2}$ levels was found in the mitochondria. Altogether, this dual-probe and multicolor imaging approach may offer a proven methodology for studying molecular communication events on $\mathrm{H}_{2} \mathrm{O}_{2}$-related apoptosis and also other physiological and pathological processes within different subcellular organelles.
\end{abstract}

\section{Introduction}

Apoptosis, a mode of programmed cell death, is critical for maintaining cellular homeostasis. Notably, cell apoptosis is an integrated mechanism involving in a series of signal transduction cascades and the synergistic effects of subcellular organelles. $^{1,2}$ There are many different pathways related to apoptosis including ligation of plasma membrane death receptors (the 'extrinsic' pathway) and perturbation of intracellular homeostasis (the 'intrinsic' pathway). Many organelles are major sites of integration of pro-apoptotic signaling, or damage sensing, and can sense stressful and pathogenic

College of Chemistry, Chemical Engineering and Materials Science, Collaborative Innovation Center of Functionalized Probes for Chemical Imaging in Universities of Shandong, Key Laboratory of Molecular and Nano Probes, Ministry of Education, Shandong Provincial Key Laboratory of Clean Production of Fine Chemicals, Shandong Normal University, Jinan 250014, P. R. China. E-mail: tangb@sdnu.edu.cn $\dagger$ Electronic supplementary information (ESI) available: Detailed experimental procedures, characterization of compounds, some fluorescence images. See DOI: $10.1039 / \mathrm{c} 6 \mathrm{sc} 01793 \mathrm{~b}$ alterations to initiate cell apoptosis. ${ }^{3,4}$ In particular, mitochondria-elicited and endoplasmic reticulum (ER) stress-regulated apoptosis are of wide concern. However, the interaction and interplay, as well as synergistic variations of the corresponding signal molecules, during mitochondria-triggered and ER-triggered apoptosis have not been elucidated. $\mathrm{H}_{2} \mathrm{O}_{2}$, as one type of reactive oxygen species (ROS) is an inevitable byproduct of cell metabolism and a common marker and signal molecule for oxidative stress that is associated with apoptosis..$^{5-8}$ Therefore, research on $\mathrm{H}_{2} \mathrm{O}_{2}$ biology will play a vital role in revealing the relationship between cell apoptosis and $\mathrm{H}_{2} \mathrm{O}_{2}$ as well as molecular communication within different organelle-derived apoptosis processes (signal pathways). For instance, $\mathrm{H}_{2} \mathrm{O}_{2}$ is generated in mitochondria as an early major mediator in rotenone-induced or ceramide-induced apoptosis. ${ }^{\mathbf{9} 10}$ And vice versa, $\mathrm{H}_{2} \mathrm{O}_{2}$ can induce apoptosis via a mitochondria-related apoptotic pathway., ${ }^{\mathbf{3 1}, 12}$ Excessive, or inaccurate, protein folding in the ER may lead to ER stress, and chronic or unresolved ER stress can trigger cell apoptosis, which is responsible for a significant proportion of $\mathrm{H}_{2} \mathrm{O}_{2}$ elevation. ${ }^{13-17}$ However, due to lack of ideal 
tools, the cooperation of mitochondria and ER in $\mathrm{H}_{2} \mathrm{O}_{2}$ biology during apoptosis has not been interpreted. In particular, when cells initiate the apoptotic cascades through one subcellular organelle under certain stimulation, the changes of $\mathrm{H}_{2} \mathrm{O}_{2}$ levels in the other involved organelles have not been studied up to now, which impedes the better understanding of $\mathrm{H}_{2} \mathrm{O}_{2}$-related physiology and pathology in apoptosis within different subcellular organelles. As a consequence, there is an urgent need to exploit new approaches for simultaneously visualizing $\mathrm{H}_{2} \mathrm{O}_{2}$ levels in different organelles sensitively and selectively.

Fluorescent probes are well-suited tools to map the spatial and temporal distribution of interested species within living cells. ${ }^{18-21}$ In particular, simultaneous fluorescence imaging of an active molecule in different subcellular organelles will facilitate understanding of complicated chemical and biological processes because this approach, with real time operation, can offer reliable data. Motivated to meet this need, specific conditions must be considered: (1) the probes must possess outstanding organelle-targeting abilities; (2) the probes must display distinguishable excitation or emission spectra that can be monitored simultaneously with multicolor confocal fluorescence imaging. In recent years, mounting synthetic fluorescent $\mathrm{H}_{2} \mathrm{O}_{2}$ indicators has been developed, which greatly contributes to the understanding of $\mathrm{H}_{2} \mathrm{O}_{2}$ biological chemistry. Among them, a series of organelle-targeting fluorescent probes have been exploited, especially for the mitochondria, ${ }^{22-29}$ the lysosome,$^{30-33}$ and the nucleus. ${ }^{34,35}$ However, no report in which simultaneous fluorescence imaging of hydrogen peroxide in different organelles, such as the mitochondria and ER, was presented and utilized to study the $\mathrm{H}_{2} \mathrm{O}_{2}$-related chemical events up to now.

In this study, we reported the synthesis and application of two $\mathrm{H}_{2} \mathrm{O}_{2}$-selective fluorescent probes, termed $\mathbf{M I}-\mathbf{H}_{2} \mathbf{O}_{2}$ and ER- $\mathbf{H}_{2} \mathbf{O}_{2}$, based on a boronic acid/ester deprotection ${ }^{\mathbf{3 6}-40}$

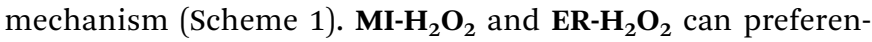
tially accumulate in the mitochondria and ER, respectively, because of the lipophilic cationic and methyl sulphonamide moieties, respectively. ${ }^{\mathbf{4 1 , 4 2}}$ Additionally, they display obviously discriminable spectra that benefits live cell multicolor imaging. $\mathbf{M I}-\mathbf{H}_{2} \mathbf{O}_{2}$ is comprised of merocyanine as a fluorescence reporter and boronic acid as a specific masking group. The boronic acid group can be removed upon reaction with hydrogen peroxide and converted to an oxygen anion, forming an intense push-pull conjugated system that fluoresces strongly (Scheme 1). Meanwhile, ER- $\mathbf{H}_{2} \mathbf{O}_{2}$ consists of a 1,8naphthalimide fluorophore and a boronic ester recognition group. After reaction of $\mathrm{H}_{2} \mathrm{O}_{2}$, an electron donor and an acceptor conformation was engendered, and that has been continually used in ratiometric fluorescent probes owing to its outstanding internal charge transfer (ICT) structure. As expected, our results indicated that $\mathbf{M I}-\mathbf{H}_{2} \mathbf{O}_{2}$ and $\mathbf{E R}-\mathbf{H}_{2} \mathbf{O}_{2}$ can visualize exogenous or endogenous $\mathrm{H}_{2} \mathrm{O}_{2}$ in mitochondria and $\mathrm{ER}$, respectively. Also, simultaneous multicolor fluorescence imaging utilizing these two probes revealed that $\mathrm{H}_{2} \mathrm{O}_{2}$ levels changed differentially in the mitochondria and the ER during different apoptotic stimuli.

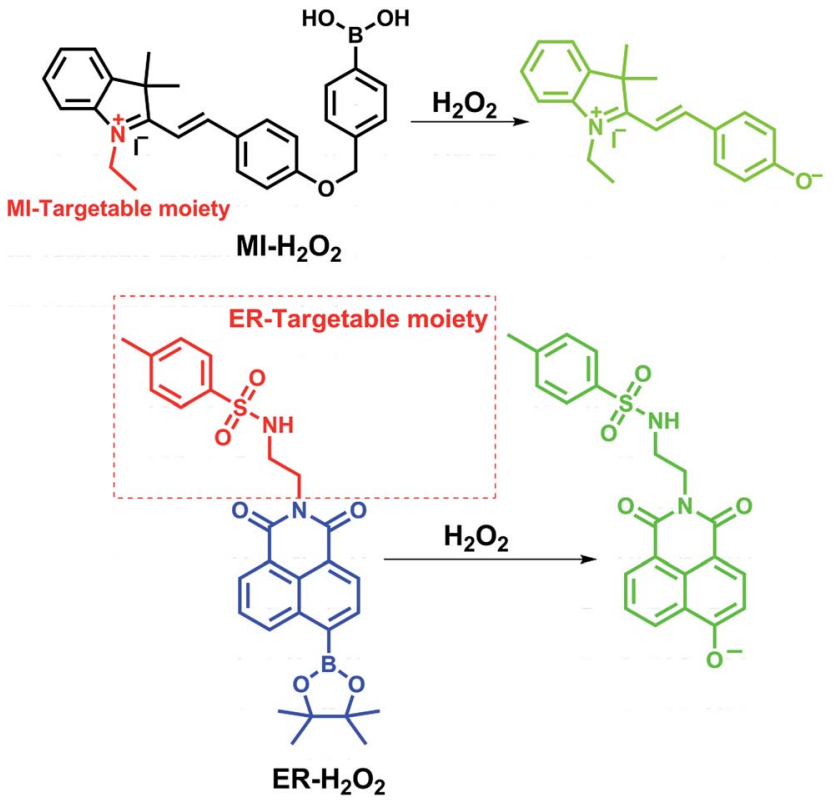

Scheme 1 The chemical structures of $\mathrm{MI}-\mathrm{H}_{2} \mathrm{O}_{2}$ and $E R-\mathrm{H}_{2} \mathrm{O}_{2}$ and corresponding response mechanism.

\section{Results and discussion}

\section{Chemical synthesis}

The target probes $\mathbf{M I}-\mathbf{H}_{2} \mathbf{O}_{2}$ and $\mathbf{E R}-\mathbf{H}_{2} \mathbf{O}_{2}$ were composed of three parts, i.e., fluorophores, recognition units, and organelletargeting moieties (Scheme 1). The fluorophores were constructed based on the merocyanine and 1,8-naphthalimide scaffolds due to their outstanding photophysical characteristics and easy preparation. The recognition units were universal boronic acid/ester and the lipophilic cationic and methyl sulphonamide served as the mitochondria and ER targeting moieties, respectively. The detailed synthetic routes of $\mathbf{M I}-\mathbf{H}_{2} \mathbf{O}_{2}$ and $\mathbf{E R}-\mathbf{H}_{2} \mathbf{O}_{2}$ are provided in the ESI. $\dagger$ All the compounds and probes were characterized by ${ }^{1} \mathrm{H}$ NMR, ${ }^{13} \mathrm{C}$ NMR and HR-MS.

\section{In vitro optical properties of $\mathrm{MI}-\mathrm{H}_{2} \mathrm{O}_{2}$ and $\mathrm{ER}-\mathrm{H}_{2} \mathrm{O}_{2}$ to $\mathrm{H}_{2} \mathrm{O}_{2}$}

To understand the effect of $\mathrm{H}_{2} \mathrm{O}_{2}$ on the photophysical properties of $\mathbf{M I}-\mathbf{H}_{2} \mathbf{O}_{2}$ and $\mathbf{E R}-\mathbf{H}_{2} \mathbf{O}_{2}$, we examined the absorption and fluorescence emission spectra of $\mathbf{M I}-\mathbf{H}_{2} \mathbf{O}_{2}$ and $\mathbf{E R}-\mathbf{H}_{2} \mathbf{O}_{2}$ in the absence and presence of $\mathrm{H}_{2} \mathrm{O}_{2}$. As shown in Fig. $1 \mathrm{~A}, \mathbf{M I}-\mathrm{H}_{2} \mathrm{O}_{2}$ was almost colorless with an absorption maximum at $425 \mathrm{~nm}$. Upon addition of $\mathrm{H}_{2} \mathrm{O}_{2}$, the solution turned to light pink with increasing absorption bands at $525 \mathrm{~nm}$. For ER- $\mathbf{H}_{2} \mathbf{O}_{2}$, its solution changed from colorless to yellow, and the absorption redshifted from $360 \mathrm{~nm}$ to $460 \mathrm{~nm}$ (Fig. 1B). This demonstrated these two probes can serve as "naked-eye" sensors for colorimetric detection of $\mathrm{H}_{2} \mathrm{O}_{2}$. We subsequently investigated the fluorescence responses of $\mathbf{M I}-\mathbf{H}_{2} \mathbf{O}_{2}$ and $\mathbf{E R}-\mathbf{H}_{2} \mathbf{O}_{2}$ to $\mathrm{H}_{2} \mathrm{O}_{2}$ under physiological conditions (10 mM PBS, pH 8.0 for $\mathbf{M I}-\mathbf{H}_{2} \mathbf{O}_{2}$ and 7.4 for $\mathbf{E R}-\mathbf{H}_{2} \mathrm{O}_{2}$ ). For $\mathbf{M I}-\mathbf{H}_{2} \mathrm{O}_{2}$, in the presence of $\mathrm{H}_{2} \mathrm{O}_{2}$, the fluorescence emission peak at $555 \mathrm{~nm}$ increased dramatically when excited at $525 \mathrm{~nm}$ (Fig. 1C). It showed an about 13-fold 


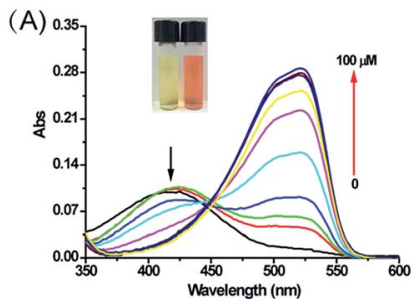

(C)
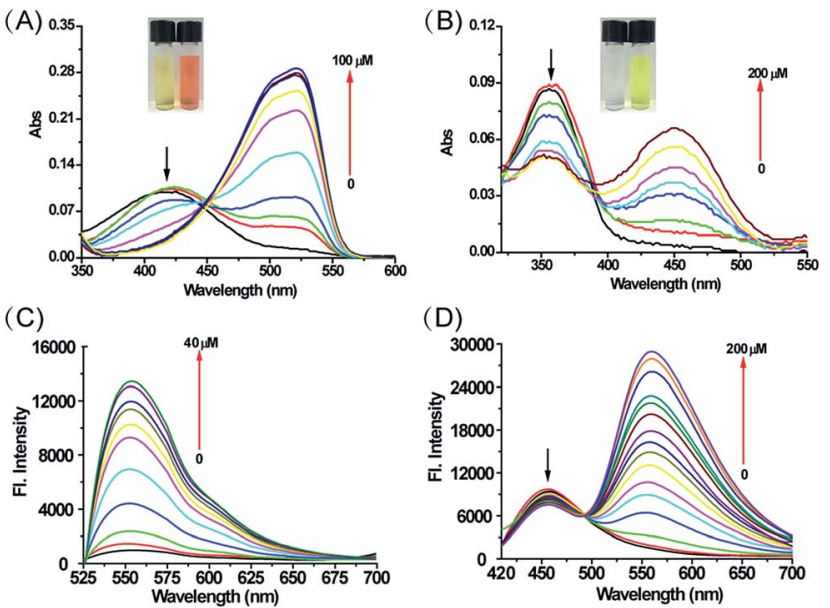

(D)

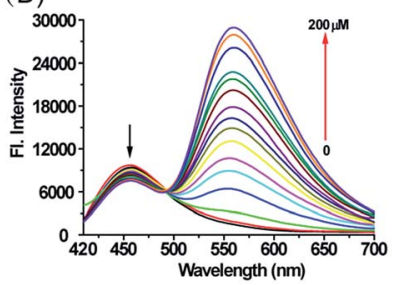

Fig. 1 The absorption and fluorescence spectra changes of $\mathrm{MI}-\mathrm{H}_{2} \mathrm{O}_{2}$ ( $A$ and $C$ ) and $E R-\mathrm{H}_{2} \mathrm{O}_{2}$ (B and D) to $\mathrm{H}_{2} \mathrm{O}_{2}$. The excitation wavelength was $525 \mathrm{~nm}$ or $400 \mathrm{~nm}$ for $\mathrm{MI}-\mathrm{H}_{2} \mathrm{O}_{2}$ and $\mathrm{ER}-\mathrm{H}_{2} \mathrm{O}_{2}$, respectively. Inset: color changes of $\mathrm{MI}-\mathrm{H}_{2} \mathrm{O}_{2}$ and $\mathrm{ER}-\mathrm{H}_{2} \mathrm{O}_{2}$ solution $(50 \mu \mathrm{M})$ in the absence or presence of $\mathrm{H}_{2} \mathrm{O}_{2}(500 \mu \mathrm{M})$.

fluorescence enhancement upon addition of $40 \mu \mathrm{M} \mathrm{H}_{2} \mathrm{O}_{2}$, and the fluorescence quantum yield increased from 0.0087 to 0.11 . Moreover, two linear regressions were obtained between the fluorescence intensity at $555 \mathrm{~nm}$ and the $\mathrm{H}_{2} \mathrm{O}_{2}$ concentration in the range of 15-40 $\mu \mathrm{M}$ and $0.5-15 \mu \mathrm{M}$ with a detection limit of $80 \mathrm{nM}$ (Fig. S1 $\dagger$ ). For ER- $\mathbf{H}_{2} \mathbf{O}_{2}$, upon addition of $\mathrm{H}_{2} \mathrm{O}_{2}$, the maximum emission peak exhibited a $100 \mathrm{~nm}$ red shift from about $458 \mathrm{~nm}$ to $558 \mathrm{~nm}$ when excited at $400 \mathrm{~nm}$, which makes $\mathbf{E R}-\mathrm{H}_{2} \mathrm{O}_{2}$ suitable for ratiometric detection due to the introduction of an electron-donating oxygen anion (Fig. 1D). It displayed an about 19-fold fluorescence enhancement at $558 \mathrm{~nm}$ upon addition of $200 \mu \mathrm{M} \mathrm{H}_{2} \mathrm{O}_{2}$, and the fluorescence quantum yield increased from 0.007 to 0.24 . The ratio $F_{558} / F_{458}$ increased from 0.161 to 3.639 in the absence and presence of $\mathrm{H}_{2} \mathrm{O}_{2}$ $(200 \mu \mathrm{M})$. There was good linearity between the fluorescence intensity ratio, $F_{558} / F_{458}$, and the concentrations of $\mathrm{H}_{2} \mathrm{O}_{2}$ in the range of 0 to $40 \mu \mathrm{M}$ with a detection limit of $120 \mathrm{nM}$ (Fig. S2 $\dagger$ ). The detection limit of $\mathbf{M I}-\mathbf{H}_{2} \mathbf{O}_{2}$ and $\mathbf{E R}-\mathbf{H}_{2} \mathbf{O}_{2}$ was favorable and comparable to many previously reported $\mathrm{H}_{2} \mathrm{O}_{2}$ sensors. ${ }^{43}$ All these results indicated that $\mathbf{M I}-\mathbf{H}_{2} \mathbf{O}_{2}$ and $\mathbf{E R}-\mathbf{H}_{2} \mathbf{O}_{2}$ could detect $\mathrm{H}_{2} \mathrm{O}_{2}$ with excellent sensitivity.

\section{The selectivity and reaction kinetics}

Afterwards we evaluated the selectivity of these two probes towards other ROS and metal ions. As illustrated in Fig. S3 and $\mathrm{S} 4, \dagger$ almost no fluorescence intensity and ratio changes were observed in the presence of $\mathrm{NaClO}, \mathrm{OH}^{*}, \mathrm{O}_{2}{ }^{-}$, $\mathrm{TBHP}, \mathrm{ONOO}^{-}$,

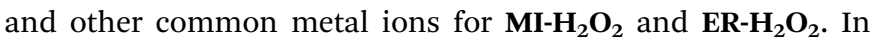
addition, the response kinetic studies for the reactions and photostable experiments were examined in Fig. S5 and S6. $\uparrow$ The pseudo-first-order rate constants were determined as $k^{\prime}=4.35$ $\times 10^{-3} \mathrm{~S}^{-1}$ and $2.35 \times 10^{-3} \mathrm{~S}^{-1}$ for the reaction of $\mathbf{M I}-\mathbf{H}_{2} \mathbf{O}_{2}$ and ER- $\mathrm{H}_{2} \mathrm{O}_{2}$ with 100 equiv. of $\mathrm{H}_{2} \mathrm{O}_{2}$ respectively. All of the above experiments imply that both $\mathbf{M I}-\mathbf{H}_{2} \mathbf{O}_{2}$ and $\mathbf{E R}-\mathbf{H}_{2} \mathbf{O}_{2}$ possess high selectivity and reaction speed to $\mathrm{H}_{2} \mathrm{O}_{2}$ as well as excellent photostability before and after reaction with $\mathrm{H}_{2} \mathrm{O}_{2}$.

\section{Organelle-targeting ability of $\mathrm{MI}-\mathrm{H}_{2} \mathrm{O}_{2}$ and ER- $\mathrm{H}_{2} \mathrm{O}_{2}$}

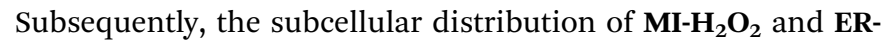
$\mathbf{H}_{2} \mathbf{O}_{2}$ in HepG2 cells were studied. As shown in Fig. 2A-D, fluorescence of $\mathbf{M I}-\mathbf{H}_{2} \mathrm{O}_{2}$ was well co-localized with that of MitoTracker Deep Red (overlap coefficient 0.90), the commercial mitochondria-specific dye, which demonstrated that $\mathbf{M I}-\mathbf{H}_{2} \mathbf{O}_{2}$ exhibited excellent mitochondria-targeting abilities that are attributable to the lipophilic cationic merocyanine moiety. At the same time, the commercial specific staining probe

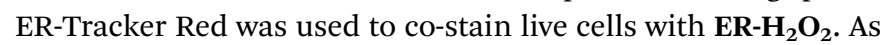

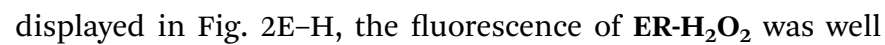
co-localized with that of ER-Tracker Red with an overlap coefficient of 0.91 . The results verified our design and implied a preferential distribution of $\mathbf{M I}-\mathbf{H}_{2} \mathbf{O}_{2}$ and $\mathbf{E R}-\mathbf{H}_{2} \mathbf{O}_{2}$ into the mitochondria and ER, respectively. Furthermore, the intrinsic organelle-targeting ability of $\mathbf{M I -} \mathbf{H}_{2} \mathbf{O}_{2}$ and $\mathbf{E R}-\mathbf{H}_{2} \mathbf{O}_{2}$ was investigated in $4 \mathrm{~T} 1$ cells. A consistent and perfect targeting capability was found (Fig. S7 $\dagger$ ). In addition, the MTT assay indicated MI- $\mathbf{H}_{2} \mathbf{O}_{2}$ and $\mathbf{E R}-\mathbf{H}_{2} \mathbf{O}_{2}$ had low cytotoxicity (Fig. S8 $\dagger$ ).

With these two excellent organelle-targeting probes in hand, we next intended to explore their optical performance in live cells. To completely avoid the spectral overlap for confocal fluorescence imaging, we chose $543 \mathrm{~nm}$ as excitation wavelength for $\mathbf{M I}-\mathbf{H}_{2} \mathbf{O}_{2}$. It is because $\mathbf{E R}-\mathbf{H}_{2} \mathbf{O}_{2}$ cannot be excited at $543 \mathrm{~nm}$, but can be easily excited by $405 \mathrm{~nm}$. In stark contrast, fluorescence enhancement of $\mathbf{M I}-\mathrm{H}_{2} \mathrm{O}_{2}$ by $\mathrm{H}_{2} \mathrm{O}_{2}$ can be readily excited by $543 \mathrm{~nm}$ but not $405 \mathrm{~nm}$ (Fig. S9†). This enabled multicolor fluorescence imaging simultaneously utilizing ER$\mathbf{H}_{2} \mathbf{O}_{2}$ and $\mathbf{M I}-\mathbf{H}_{2} \mathbf{O}_{2}$ by excitation wavelengths of 405 and 543 $\mathrm{nm}$, respectively. Therefore, we performed the confocal fluorescence imaging of $\mathrm{H}_{2} \mathrm{O}_{2}$ in live cells with both $\mathbf{E R}-\mathbf{H}_{2} \mathbf{O}_{2}$
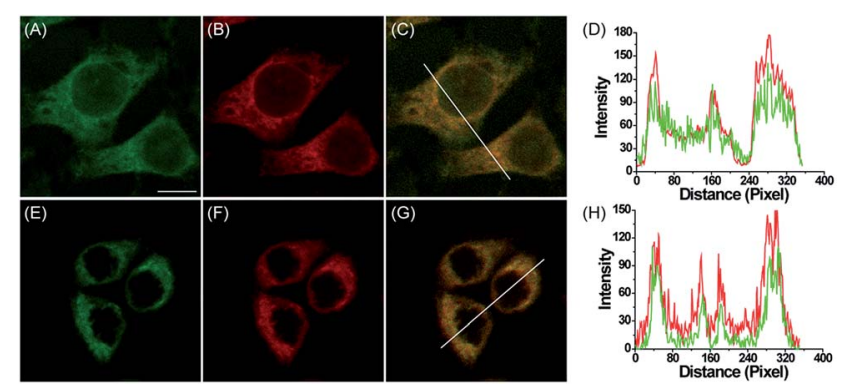

Fig. 2 Confocal fluorescence images of HepG2 cells stained with MI$\mathrm{H}_{2} \mathrm{O}_{2}$ or ER- $\mathrm{H}_{2} \mathrm{O}_{2}$ with corresponding commercial organelle-specific dyes. (A) Fluorescence image of $\mathrm{MI}-\mathrm{H}_{2} \mathrm{O}_{2}(10 \mu \mathrm{M}$, green channel, Ex = $514 \mathrm{~nm}$, collected $520-580 \mathrm{~nm}$ ) in cells pretreated with $200 \mu \mathrm{M} \mathrm{H}_{2} \mathrm{O}_{2}$ for $60 \mathrm{~min}$. (B) Fluorescence image of Mito-Tracker Deep Red $(0.5 \mu \mathrm{M}$, red channel, Ex $=633 \mathrm{~nm}$, collected 640-700 nm). (C) Overlay of (A) and (B). (D) Intensity profile of the white line in image $C$. (E) Fluorescence image of ER- $\mathrm{H}_{2} \mathrm{O}_{2}(10 \mu \mathrm{M}$, green channel, $\mathrm{Ex}=405 \mathrm{~nm}$, collected 500-620 nm) in cells pretreated with $200 \mu \mathrm{M} \mathrm{H}_{2} \mathrm{O}_{2}$ for 60 min. (F) Fluorescence image of ER-Tracker Red $(0.5 \mu \mathrm{M}$, red channel, $E x=543 \mathrm{~nm}$, collected 580-630 nm). (G) Overlay of (E) and (F). (H) Intensity profile of the white line in image G. Scale bar: $10 \mu \mathrm{m}$. 
and $\mathbf{M I}-\mathrm{H}_{2} \mathrm{O}_{2}$. After treating with $200 \mu \mathrm{M} \mathrm{H} \mathrm{H}_{2} \mathrm{O}_{2}$ for $1 \mathrm{~h}$, HepG2 cells were incubated with $\mathbf{E R}-\mathbf{H}_{2} \mathbf{O}_{2}$ and $\mathbf{M I}-\mathbf{H}_{2} \mathbf{O}_{2}$ for $1 \mathrm{~h}$, and the probes can fluoresce well under excitation of 405 and $543 \mathrm{~nm}$. As shown in Fig. 3E, there is basically no overlap fluorescence between the green channel of $\mathbf{E R}-\mathbf{H}_{2} \mathbf{O}_{2}$ (image A, excited by $405 \mathrm{~nm}$ and collected at 500-620 nm) and the red channel of $\mathbf{M I}-\mathbf{H}_{2} \mathbf{O}_{2}$ (image C, excited by $543 \mathrm{~nm}$ and collected at 550-600 $\mathrm{nm})$. An enlarged image from Fig. 3E indicated it indeed exhibited remarkable intensity difference in these two images (Fig. 3F). All the date established $\mathbf{E R}-\mathbf{H}_{2} \mathbf{O}_{2}$ and $\mathbf{M I}-\mathbf{H}_{2} \mathbf{O}_{2}$ have differentiable excitation and emission spectra and enable multicolor fluorescence imaging of exogenous $\mathrm{H}_{2} \mathrm{O}_{2}$ in the mitochondria and the ER simultaneously.

Endogenous $\mathrm{H}_{2} \mathrm{O}_{2}$ imaging in live cells with $\mathrm{MI}-\mathrm{H}_{2} \mathrm{O}_{2}$ and ER$\mathrm{H}_{2} \mathrm{O}_{2}$

We next visualized the endogenous $\mathrm{H}_{2} \mathrm{O}_{2}$ in live cells induced by different stimulus in the mitochondria and the ER respectively. Phorbol 12-myristate 13-acetate (PMA) may trigger production of ROS in mitochondria via activating of PKC (protein kinase C). ${ }^{44}$ The fluorescence of $\mathbf{M I}-\mathbf{H}_{2} \mathbf{O}_{2}$ increased obviously upon addition of PMA for $60 \mathrm{~min}$ (Fig. S10A $\dagger$ ). Tunicamycin (Tm) produced by several bacteria, is known to inhibit glycosylation during protein or glycolipid synthesis, which can cause the accumulation of proteins or lipids in the ER, leading to acute ER stress. ${ }^{45}$ To image the endogenous production of $\mathrm{H}_{2} \mathrm{O}_{2}$ in live cells by utilizing $\mathbf{E R}-\mathbf{H}_{2} \mathbf{O}_{2}$ in this condition, we performed the ratiometric fluorescence imaging of Tm-treated HepG2 cells. As illustrated in Fig. S10B, $\dagger$ Tm-treated $\left(10 \mu \mathrm{g} \mathrm{mL} \mathrm{m}^{-1}, 8 \mathrm{~h}\right)$ cells showed obviously bright fluorescence in the green channel compared to that of DMSO-treated cells (Fig. S10B6 and B2 $\dagger$ ). The ratiometric image between the two channels (green to blue) further validated that $\mathrm{H}_{2} \mathrm{O}_{2}$ was produced in this Tm-induced
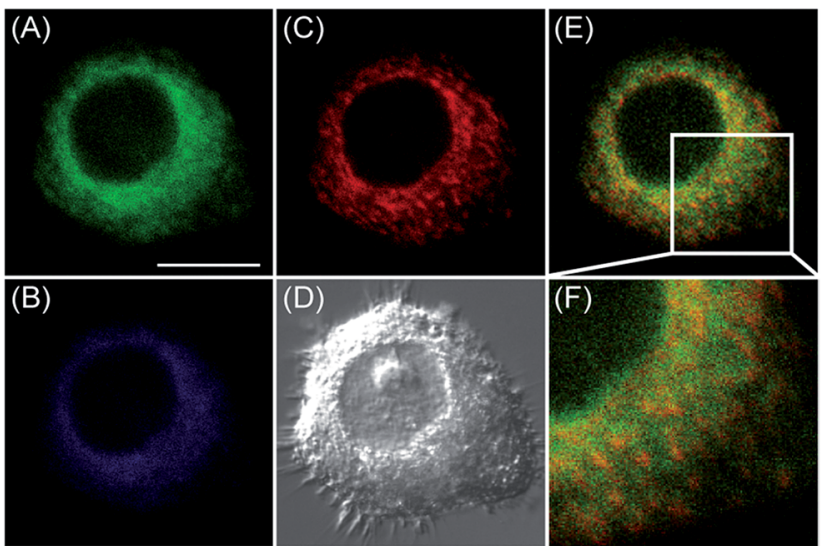

Fig. 3 Confocal fluorescence images of live $\mathrm{HepG} 2$ cells stained simultaneously with ER- $\mathrm{H}_{2} \mathrm{O}_{2}$ and $\mathrm{MI}-\mathrm{H}_{2} \mathrm{O}_{2}(10 \mu \mathrm{M}) . \mathrm{ER}-\mathrm{H}_{2} \mathrm{O}_{2}$ was excited by $405 \mathrm{~nm}$, and collected at 500-620 nm for the green channel (image A) and at 430-470 $\mathrm{nm}$ for the blue channel (image B). $\mathrm{MI}-\mathrm{H}_{2} \mathrm{O}_{2}$ was excited by $543 \mathrm{~nm}$, and collected at $550-600 \mathrm{~nm}$ for the red channel (image $C$ ). (D) was the bright-field image. (E) was overlay of $(A)$ and $(C)$. (F) was the enlarged image from the square marked in image (E). Scare bar: $20 \mu \mathrm{m}$.
ER stress model (Fig. S10B7 and B3 $\dagger$ ). The similar results were observed in the mouse 4T1 cells (Fig. S11†). In addition, ER$\mathrm{H}_{2} \mathrm{O}_{2}$ was utilized to detect the production of $\mathrm{H}_{2} \mathrm{O}_{2}$ in live cells treated with dithiothreitol (DTT), a reducing agent that can disturb the formation of protein disulfide bonds and induce ER stress. $^{46,47}$ The results presented in Fig. S12 $\dagger$ displayed that there was an obvious fluorescence increase in the green channel, indicating a rise in the $\mathrm{H}_{2} \mathrm{O}_{2}$ concentration. Furthermore, to explore whether there is a burst of $\mathrm{H}_{2} \mathrm{O}_{2}$ concentration in live cells treated with anticancer drugs targeting the ER, ER$\mathbf{H}_{2} \mathbf{O}_{2}$ was applied for fluorescence imaging in live HepG2 cells treated with nelfinavir, a lead HIV protease inhibitor and broadspectrum anticancer drug that can lead to ER stress. ${ }^{4-50}$ As shown in Fig. S13, $\dagger$ upon treated with $200 \mu \mathrm{g} \mathrm{mL}{ }^{-1}$ nelfinavir for $160 \mathrm{~min}$, the fluorescence intensity of the green channel increased (Fig. S13B and $\mathrm{F}^{\dagger}$ ) and the ratio between the green channel and the blue channel was higher (Fig. S13C and G†). Additionally, the cells showed shrinking morphological changes (Fig. S13D and $\mathrm{H} \dagger$ ), indicating the apoptosis of cells involved in the ER-stress pathway. At the same time, a similar experimental result was observed in the nelfinavir-induced 4T1 cells (Fig. S14 $\dagger$ ). Collectively, all this data demonstrated that MI$\mathbf{H}_{2} \mathrm{O}_{2}$ and ER- $\mathbf{H}_{2} \mathrm{O}_{2}$ can image endogenous $\mathrm{H}_{2} \mathrm{O}_{2}$ well in the corresponding subcellular organelles under different stimuli.

\section{Simultaneous fluorescence imaging of $\mathrm{H}_{2} \mathrm{O}_{2}$ with $\mathrm{MI}-\mathrm{H}_{2} \mathrm{O}_{2}$ and ER- $\mathrm{H}_{2} \mathrm{O}_{2}$ during apoptosis with different stimuli}

In an effort to explore the practicability of $\mathbf{E R}-\mathbf{H}_{2} \mathbf{O}_{2}$ and MI$\mathrm{H}_{2} \mathrm{O}_{2}$ for the simultaneous imaging of $\mathrm{H}_{2} \mathrm{O}_{2}$ in live cells, we first carried out fluorescence imaging of $\mathrm{H}_{2} \mathrm{O}_{2}$ in $4 \mathrm{~T} 1$ cells treated with apoptotic stimulant i.e. L-buthionine sulfoximine (BSO). BSO is an inhibitor of gamma glutamyl cysteine synthetase ( $\gamma$ GCS), which can induce a decline of glutathione (GSH) and increase of ROS within the whole cell that further results in cell apoptotic behavior. ${ }^{51}$ The $4 \mathrm{~T} 1$ cells were simultaneously incubated with $\mathbf{E R}-\mathbf{H}_{2} \mathbf{O}_{2}$ and $\mathbf{M I}-\mathbf{H}_{2} \mathbf{O}_{2}$ for $30 \mathrm{~min}$ at $37^{\circ} \mathrm{C}$. Then, the cells were washed three times with $\mathrm{PBS}$ after the incubation medium was removed. BSO (5 $\mathrm{mM})$ was added to induce apoptosis. As shown in Fig. 4, when the 4T1 cells were treated with BSO for various times, the fluorescence intensity of ER$\mathbf{H}_{2} \mathbf{O}_{2}$ (green channel) and $\mathbf{M I}-\mathbf{H}_{2} \mathbf{O}_{2}$ (red channel) gradually elevated simultaneously, implying the $\mathrm{H}_{2} \mathrm{O}_{2}$ concentration increased in both mitochondria and ER. At the same time, the shrinking morphologic changes of cells were observed, indicating the occurrence of apoptosis. A similar result was found in the HepG2 cells incubated with higher concentrations of BSO at different times (Fig. S15 $\dagger$ ). These results displayed that $\mathrm{H}_{2} \mathrm{O}_{2}$ levels both in the mitochondria and ER would rise during BSO induced apoptosis, presumably because attenuation of cellular GSH levels induced by BSO disturbed the cellular redox status.

Inspired by the above interesting results, we next intended to investigate the synergistic variations of $\mathrm{H}_{2} \mathrm{O}_{2}$ levels within these two organelles in cells treated with organelle-specific apoptotic stimuli. We first examined the changes on $\mathrm{H}_{2} \mathrm{O}_{2}$ levels in HepG2 cells treated with carbonyl cyanide $m$-chlorophenylhydrazone (CCCP). CCCP, an un-coupler of mitochondrial photophosphorylation, can 


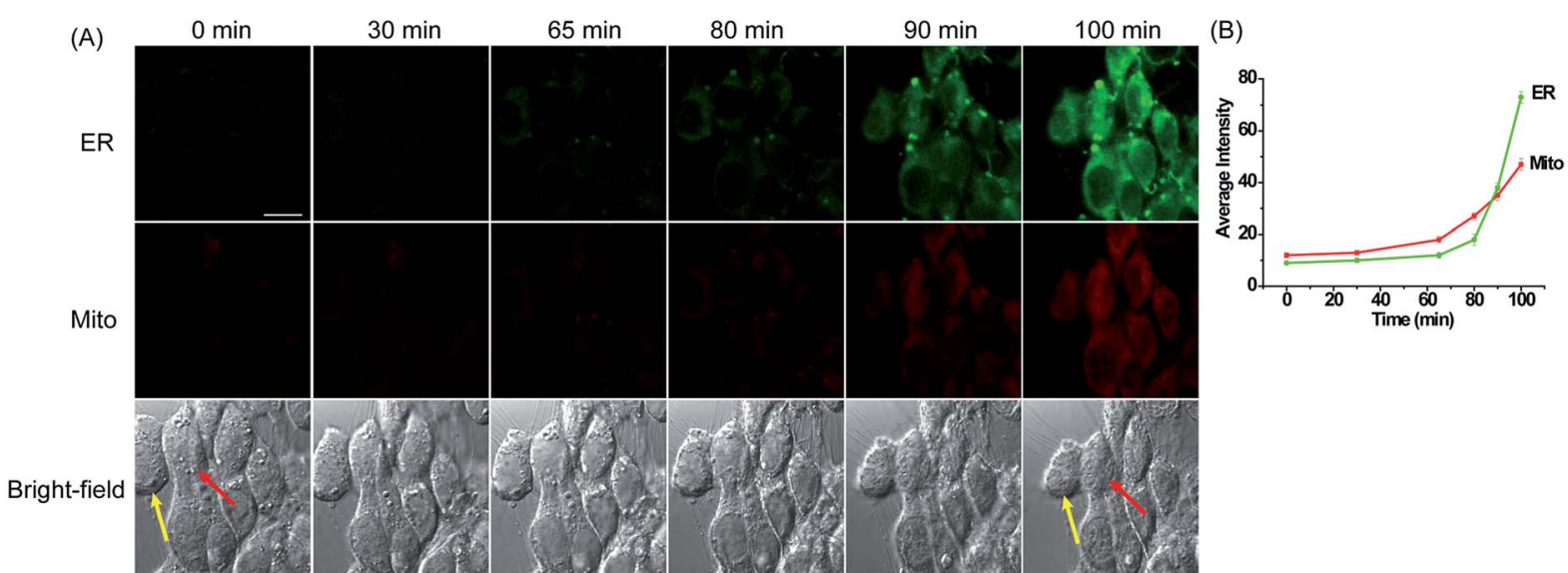

Fig. 4 (A) Confocal fluorescence images of $4 \mathrm{T1}$ cells stained simultaneously with $\mathrm{ER}-\mathrm{H}_{2} \mathrm{O}_{2}$ and $\mathrm{MI}-\mathrm{H}_{2} \mathrm{O}_{2}(10 \mu M)$ in the presence of BSO (5 mM) at different times. The first row (green channel) contains fluorescence images for ER- $\mathrm{H}_{2} \mathrm{O}_{2}$ collected at $500-620 \mathrm{~nm}$ by excitation at $405 \mathrm{~nm}$. The second row (red channel) contains fluorescence images for $\mathrm{MI}_{-} \mathrm{H}_{2} \mathrm{O}_{2}$ collected at 550-600 nm by excitation at $543 \mathrm{~nm}$. The third row contains bright-field images. (B) The output of average fluorescence intensity changes in image A at different times. Scale bar: $20 \mu m$.

induce apoptosis through a mitochondria-dependent pathway by disturbing the mitochondrial membrane potential, which can increase ROS generation in mitochondria. ${ }^{52,53}$ To explore the variations of $\mathrm{H}_{2} \mathrm{O}_{2}$ levels in the ER under this stimulant, the HepG2 cells were simultaneously incubated with $\mathbf{E R}-\mathbf{H}_{2} \mathbf{O}_{2}$ and $\mathbf{M I}-\mathbf{H}_{2} \mathbf{O}_{2}$ for $30 \mathrm{~min}$ at $37^{\circ} \mathrm{C}$. Then, the cells were washed three times with PBS after the incubation medium was removed. CCCP $(100 \mu \mathrm{M})$ was added to induce mitochondria-oriented apoptosis. As indicated in Fig. 5, when the HepG2 cells were treated with CCCP for various times, the fluorescence intensity of $\mathbf{M I}-\mathbf{H}_{2} \mathbf{O}_{2}$ (red channel) gradually enhanced, indicating the elevation of $\mathrm{H}_{2} \mathrm{O}_{2}$ levels in the mitochondria under this stimulus. Whereas, the fluorescence intensity of ER- $\mathbf{H}_{2} \mathbf{O}_{2}$ (green channel) was weak for the first $20 \mathrm{~min}$, indicating no rise of $\mathrm{H}_{2} \mathrm{O}_{2}$ in the ER under CCCP induced apoptosis in the initial stage. However, the persistent stimulus resulted in a moderate fluorescence increase of $\mathbf{E R}-\mathbf{H}_{2} \mathbf{O}_{2}$, suggesting a rise of $\mathrm{H}_{2} \mathrm{O}_{2}$ in the ER. In addition, the fluorescence imaging of HepG2 cells induced by rotenone, ${ }^{54,55}$ an inhibitor of mitochondrial respiratory chain complex I, produced similar results. $\mathrm{H}_{2} \mathrm{O}_{2}$ levels remained elevated in the mitochondria and a delayed rise in $\mathrm{H}_{2} \mathrm{O}_{2}$ levels occurred in the ER (Fig. S16†). All of this data showed that $\mathrm{H}_{2} \mathrm{O}_{2}$ levels prominently and continuously increased in mitochondria during mitochondria-oriented apoptotic stimulus, and sustaining apoptosis led to a subsequent $\mathrm{H}_{2} \mathrm{O}_{2}$ rise in the ER. The reason presumably results from the fact that dysfunction of mitochondria may elicit interplay with other organelles, ${ }^{4}$ such as the ER, the lysosome, and the nucleus, which may promote the coordinated variation of active molecules or inter-organellar cross-talk.

At last, ER- $\mathbf{H}_{2} \mathbf{O}_{2}$ and $\mathbf{M I}-\mathbf{H}_{2} \mathbf{O}_{2}$ were utilized for simultaneous fluorescence imaging of $\mathrm{H}_{2} \mathrm{O}_{2}$ in $4 \mathrm{~T} 1$ cells treated with Tm, an ER-oriented apoptotic stimulant. To explore whether the $\mathrm{H}_{2} \mathrm{O}_{2}$ levels would change in the mitochondria under this stimulant,

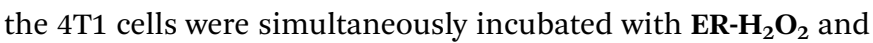
$\mathbf{M I}-\mathbf{H}_{2} \mathbf{O}_{2}$ for $30 \mathrm{~min}$ at $37{ }^{\circ} \mathrm{C}$. Then, cells were washed three

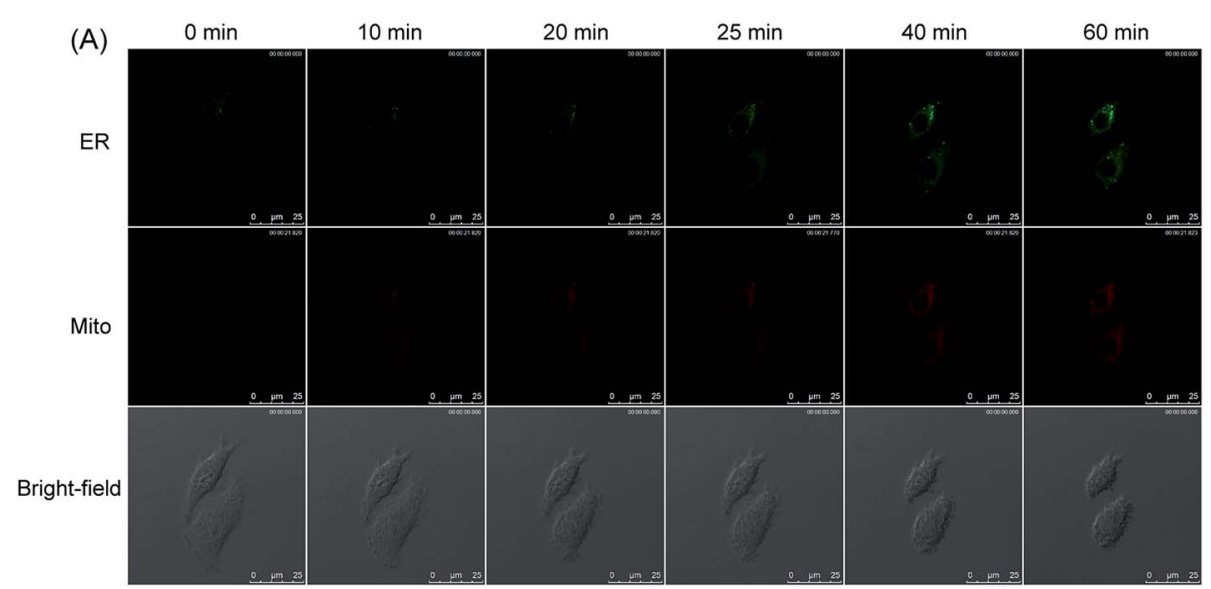

(B)

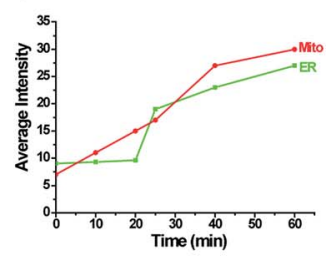

Fig. 5 (A) Confocal fluorescence images of HepG2 cells stained simultaneously with ER- $\mathrm{H}_{2} \mathrm{O}_{2}$ and $\mathrm{MI}-\mathrm{H}_{2} \mathrm{O}_{2}(10 \mu \mathrm{M})$ in the presence of CCCP $(100 \mu \mathrm{M})$ at different times. The first row (green channel) contains fluorescence images for $\mathrm{ER}-\mathrm{H}_{2} \mathrm{O}_{2}$ collected at $500-620 \mathrm{~nm}$ by the excitation at $405 \mathrm{~nm}$. The second row (red channel) contains fluorescence images for $\mathrm{Ml}-\mathrm{H}_{2} \mathrm{O}_{2}$ collected at $550-600 \mathrm{~nm}$ by the excitation at $543 \mathrm{~nm}$. The third row contains bright-field images. (B) The output of average fluorescence intensity changes in image (A) at different times. Scale bar: $25 \mu \mathrm{m}$. 


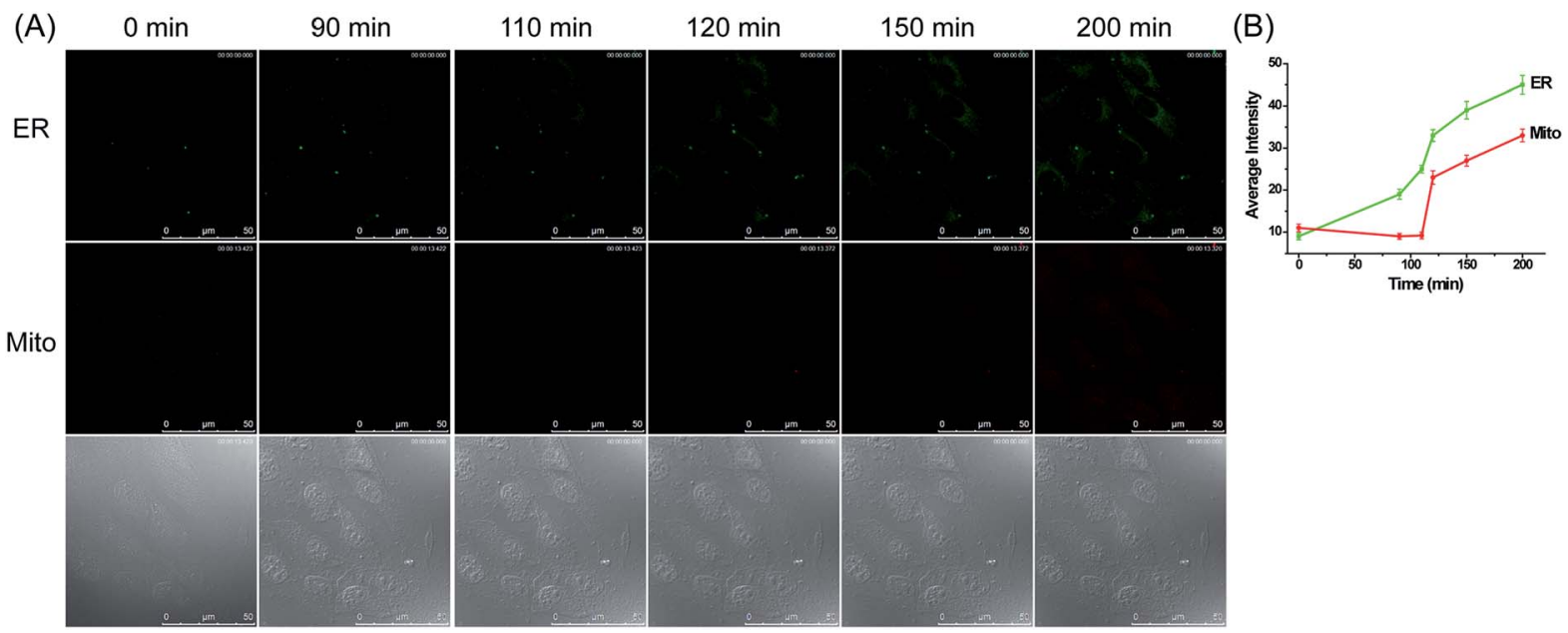

Fig. 6 (A) Confocal fluorescence images of $4 \mathrm{~T} 1$ cells stained simultaneously with ER- $\mathrm{H}_{2} \mathrm{O}_{2}$ and $\mathrm{MI}-\mathrm{H}_{2} \mathrm{O}_{2}(10 \mu \mathrm{M})$ in the presence of Tm (100 $\mu \mathrm{g}$ $\mathrm{mL}^{-1}$ ) at different times. The first row (green channel) contains fluorescence images for $\mathrm{ER}-\mathrm{H}_{2} \mathrm{O}_{2}$ collected at $500-620 \mathrm{~nm}$ by the excitation at $405 \mathrm{~nm}$. The second row (red channel) contains fluorescence images for $\mathrm{Ml}^{-} \mathrm{H}_{2} \mathrm{O}_{2}$ collected at 550-600 nm by the excitation at $543 \mathrm{~nm}$. The third row contains bright-field images. (B) The output of average fluorescence intensity changes in image A at different times. Scale bar: $50 \mu \mathrm{m}$.

times with PBS after the incubation medium was removed. Tm $\left(100 \mu \mathrm{g} \mathrm{mL}{ }^{-1}\right)$ was added to induce ER-associated apoptosis. As illustrated in Fig. 6, when the 4T1 cells were treated with Tm for various times, the fluorescence intensity of $\mathbf{E R}-\mathbf{H}_{2} \mathbf{O}_{2}$ (green channel) gradually enhanced from about $90 \mathrm{~min}$ after addition of $\mathrm{Tm}$, indicating the rise of $\mathrm{H}_{2} \mathrm{O}_{2}$ concentration in the ER under this stimulus. In the meantime, the fluorescence intensity of $\mathbf{M I}-\mathbf{H}_{2} \mathbf{O}_{2}$ was weak and almost stable within $120 \mathrm{~min}$, and the fluorescence intensity increased progressively from $120 \mathrm{~min}$ to $200 \mathrm{~min}$. All this data demonstrated that ER stress-derived apoptosis will upgrade $\mathrm{H}_{2} \mathrm{O}_{2}$ levels within the ER. Meanwhile, a delayed rise in $\mathrm{H}_{2} \mathrm{O}_{2}$ levels was observed in the mitochondria. We speculate that this phenomenon probably resulted from direct diffusion of $\mathrm{H}_{2} \mathrm{O}_{2}$ among different compartments ${ }^{56,57}$ or indirect generation in the mitochondria stimulated by calcium influx from the ER to the mitochondria during conditions of ER stress. ${ }^{58}$

\section{Conclusions}

In conclusion, we have presented the application of two organelle-targeting fluorescent probes termed $\mathbf{M I}-\mathbf{H}_{2} \mathbf{O}_{2}$ and ER$\mathbf{H}_{2} \mathrm{O}_{2}$ for imaging $\mathrm{H}_{2} \mathrm{O}_{2}$ in the mitochondria and the ER of live cells during apoptosis with real-time operability and reliability. The data shows that ER- $\mathbf{H}_{2} \mathbf{O}_{2}$ and $\mathbf{M I}-\mathbf{H}_{\mathbf{2}} \mathbf{O}_{2}$ can selectively and sensitively detect exogenous and endogenous $\mathrm{H}_{2} \mathrm{O}_{2}$ under a myriad of stimuli. More importantly, $\mathbf{M I}-\mathbf{H}_{2} \mathbf{O}_{2}$ and $\mathbf{E R}-\mathbf{H}_{2} \mathbf{O}_{2}$ display distinct excitation and emission spectra, which favors multicolor fluorescence imaging in live cells. By utilizing MI$\mathbf{H}_{2} \mathbf{O}_{2}$ and $\mathbf{E R}-\mathbf{H}_{2} \mathrm{O}_{2}$ for simultaneous fluorescence imaging of $\mathrm{H}_{2} \mathrm{O}_{2}$ in live cells, we found that the variations in $\mathrm{H}_{2} \mathrm{O}_{2}$ levels in the mitochondria and the ER were different during apoptosis induced by various stimuli. $\mathrm{H}_{2} \mathrm{O}_{2}$ levels were enhanced in both the mitochondria and the ER during the BSO-treated apoptosis process. During mitochondria-related apoptosis, $\mathrm{H}_{2} \mathrm{O}_{2}$ levels are prominently and consistently increased in the mitochondria, and subsequently $\mathrm{H}_{2} \mathrm{O}_{2}$ elevation was found in the ER. Whereas, during ER-associated apoptosis, the ER is the major site for overproduction of $\mathrm{H}_{2} \mathrm{O}_{2}$, while a delayed rise in $\mathrm{H}_{2} \mathrm{O}_{2}$ levels was also observed in the mitochondria. Although precise $\mathrm{H}_{2} \mathrm{O}_{2}$ biology during apoptosis involving the mitochondria and the ER should be further studied, this was the first example of simultaneous fluorescence imaging of $\mathrm{H}_{2} \mathrm{O}_{2}$ in the mitochondria and the ER during apoptosis. This may offer a useful platform for further elucidating the molecular mechanism of apoptosis regulated by different organelles.

\section{Acknowledgements}

This work was supported by 973 Program (2013CB933800) and National Natural Science Foundation of China (21390411, 21535004, 21227005, and 21475079).

\section{Notes and references}

1 N. N. Danial and S. J. Korsmeyer, Cell, 2004, 116, 205-219.

2 S. Elmore, Toxicol. Pathol., 2007, 35, 495-516.

3 H. U. Simon, A. Haj-Yehia and F. Levi-Schaffer, Apoptosis, 2000, 5, 415-418.

4 K. F. Ferri and G. Kroemer, Nat. Cell Biol., 2001, 3, E255E263.

5 J. A. Imlay, Annu. Rev. Biochem., 2008, 77, 755-776.

6 E. Cadenas and K. J. A. Davies, Free Radical Biol. Med., 2000, 29, 222-230.

7 M. Ott, V. Gogvadze, S. Orrenius and B. Zhivotovsky, Apoptosis, 2007, 12, 913-922.

8 T. Finkel and N. J. Holbrook, Nature, 2000, 408, 239-247.

9 A. Quillet-Mary, J. P. Jaffrezou, V. Mansat, C. Bordier, J. Naval and G. Laurent, J. Biol. Chem., 1997, 272, 21388-21395. 
10 S. Tada-Oikawa, Y. Hiraku, M. Kawanishi and S. Kawanishi, Life Sci., 2003, 73, 3277-3288.

11 C. Fleury, B. Mignotte and J. Vayssière, Biochimie, 2002, 84, 131-141.

12 M. Giorgio, M. Trinei, E. Migliaccio and P. G. Pelicci, Nat. Rev. Mol. Cell Biol., 2007, 8, 722-728.

13 E. Gross, C. S. Sevier, N. Heldman, E. Vitu, M. Bentzur, C. A. Kaiser, C. Thorpe and D. Fass, Proc. Natl. Acad. Sci. U. S. A., 2006, 103, 299-304.

14 C. S. Sevier and C. A. Kaiser, Biochim. Biophys. Acta, 2008, 1783, 549-556.

15 G. S. Hotamisligil, Cell, 2010, 140, 900-917.

16 B. P. Tu and J. S. Weissman, J. Cell Biol., 2004, 164, 341-346. 17 É. Margittai, B. Enyedi, M. Csala, M. Geiszt and G. Bánhegyi, Free Radical Biol. Med., 2015, 83, 331-340.

18 J. Chan, S. C. Dodani and C. J. Chang, Nat. Chem., 2012, 4, 973-984.

19 Y. Tang, D. Lee, J. Wang, G. Li, J. Yu, W. Lin and J. Yoon, Chem. Soc. Rev., 2015, 44, 5003-5015.

20 J. Yin, Y. Hua and J. Yoon, Chem. Soc. Rev., 2015, 44, 46194644.

21 T. Terai and T. Nagano, Curr. Opin. Chem. Biol., 2008, 12, 515-521.

22 D. Srikun, A. E. Albers, C. I. Nam, A. T. Iavaron and C. J. Chang, J. Am. Chem. Soc., 2010, 132, 4455-4465.

23 L. Yang, N. Li, W. Pan, Z. Yu and B. Tang, Anal. Chem., 2015, 87, 3678-3684.

24 B. C. Dickinson and C. J. Chang, J. Am. Chem. Soc., 2008, 130, 9638-9639.

25 B. C. Dickinson, D. Srikun and C. J. Chang, Curr. Opin. Chem. Biol., 2010, 14, 50-56.

26 B. C. Dickinson, V. S. Lin and C. J. Chang, Nat. Protoc., 2013, 8, 1249-1259.

27 G. Masanta, C. H. Heo, C. S. Lim, S. K. Bae, B. R. Cho and H. M. Kim, Chem. Commun., 2012, 48, 3518-3520.

28 H. Guo, H. Aleyasin, S. S. Howard, B. C. Dickinson, V. S. Lin, R. E. Haskew-Layton, C. Xu, Y. Chen and R. R. Ratan, J. Biomed. Opt., 2013, 18, 106002-106007.

29 J. Xu, Y. Zhang, H. Yu, X. Gao and S. Shao, Anal. Chem., 2015, 1-19.

30 D. Kim, G. Kim, S. J. Nam, J. Yin and J. Yoon, Sci. Rep., 2015, 5, 8488 .

31 D. Song, J. M. Lim, S. Cho, S. J. Park, J. Cho, D. Kang, S. G. Rhee, Y. You and W. Nam, Chem. Commun., 2012, 48, 5449-5451.

32 M. Ren, B. Deng, J. Y. Wang, X. Kong, Z. R. Liu, K. Zhou, L. He and W. Lin, Biosens. Bioelectron., 2015, 79, 237-243.

33 J. Jing and J. L. Zhang, Chem. Sci., 2013, 4, 2947-2952.

34 B. C. Dickinson, Y. Tang, Z. Chang and C. J. Chang, Chem. Biol., 2011, 18, 943-948.

35 Y. Wen, K. Y. Liu, H. R. Yang, Y. Li, H. C. Lan, Y. Liu, X. Y. Zhang and T. Yi, Anal. Chem., 2014, 86, 9970-9976.
36 D. Srikun, E. W. Miller, D. W. Domaille and C. J. Chang, J. Am. Chem. Soc., 2008, 130, 4596-4597.

37 B. C. Dickinson, C. Huynh and C. J. Chang, J. Am. Chem. Soc., 2010, 132, 5906-5915.

38 A. E. Albers, V. S. Okreglak and C. J. Chang, J. Am. Chem. Soc., 2006, 128, 9640-9641.

39 M. C. Y. Chang, A. Pralle, E. Y. Isacoff and C. J. Chang, J. Am. Chem. Soc., 2004, 126, 15392-15393.

40 E. W. Miller, A. E. Albers, A. Pralle, E. Y. Isacoff and C. J. Chang, J. Am. Chem. Soc., 2005, 127, 16652-16659.

41 A. T. Hoye, J. E. Davoren and P. Wipf, Acc. Chem. Res., 2008, 41, 87-97.

42 B. K. McMahon, R. Pal and D. Parker, Chem. Commun., 2013, 49, 5363-5365.

43 K. Żamojć, M. Zdrowowicz, D. Jacewicz, D. Wyrzykowski and L. Chmurzyński, Crit. Rev. Anal. Chem., 2016, 46, 171-200.

44 M. Alasubramanyam, A. Koteswari, R. Kumar, S. Monickaraj, J. Maheswari and V. Ohan, J. Biosci., 2003, 28, 715-721.

45 T. Nakagawa, H. Zhu, N. Morishima, E. Li, J. Xu, B. A. Yankner and J. Yuan, Nature, 2000, 403, 98-103.

46 I. Braakman, J. Helenius and A. Helenius, EMBO J., 1992, 11, 1717-1722.

47 F. Cusinato, I. Pighin, S. Luciani and L. Trevisi, Biochem. Pharmacol., 2006, 71, 1562-1569.

48 P. Pyrko, A. Kardosh, W. Wang, W. Xiong, A. H. Schonthal and T. C. Chen, Cancer Res., 2007, 67, 10920-10928.

49 J. J. Gills, J. Lopiccolo, J. Tsurutani, R. H. Shoemaker, C. J. Best, M. S. Abu-Asab, J. Borojerdi, N. A. Warfel, E. R. Gardner, M. Danish, M. C. Hollander, S. Kawabata, M. Tsokos, W. D. Figg, P. S. Steeg and P. A. Dennis, Clin. Cancer Res., 2007, 13, 5183-5194.

50 J. J. Gills, J. LoPiccolo and P. A. Dennis, Autophagy, 2015, 4, 107-109.

51 J. S. Armstrong, K. K. Steinauer, B. Hornung, J. M. Irish, P. Lecane, G. W. Birrell, D. M. Peehl and S. J. Knox, Cell Death Differ., 2002, 9, 252-263.

52 R. A. Goldsby and P. G. Heytler, Biochemistry, 1963, 2, 11421147.

53 A. A. Chaudhari, J. W. Seol, S. J. Kim, Y. J. Lee, H. S. Kang, I. S. Kim, N. S. Kim and S. Y. Park, Oncol. Rep., 2007, 18, 71-76.

54 N. Li, K. Ragheb, G. Lawler, J. Sturgis, B. Rajwa, J. A. Melendez and J. P. Robinson, J. Biol. Chem., 2003, 278, 8516-8525.

55 S. Tada-Oikawa, Y. Hiraku, M. Kawanishi and S. Kawanishi, Life Sci., 2003, 73, 3277-3288.

56 M. Malinouski, Y. Zhou, V. V. Belousov, D. L. Hatfield and V. N. Gladyshev, PLoS One, 2011, 6, e14564.

57 B. Chance, H. Sies and A. Boveris, Physiol. Rev., 1979, 59, 527-605.

58 S. S. Cao and R. J. Kaufman, Antioxid. Redox Signaling, 2014, 21, 396-413. 